\title{
BEYOND ABOLITION: ETHICAL EXCHANGES WITH ANIMALS IN AGRICULTURE
}

\author{
SUSAN ISEN \\ University of North Carolina at Wilmington
}

The major focus of the animal rights movement, both philosophically and politically, has so far been on the abolition of various institutional violations of animal rights. Factory farming, hunting, trapping, whaling, and animal experimentation have been argued to be fundamental violations of animal rights and corresponding political campaigns for abolishing these institutions have been mounted. Since it is only by dismantling such institutions that the goals of the animal rights movement can be achieved, there can be no doubt that abolition is a legitimate major focus of the movement.

Nevertheless, there is a further issue which must be addressed, if abolitionist measures are to have permanent results: what are the positive exchanges and relationships we can have with animals and the environment? We must learn to peacefully and ethically coexist in the environnent with other species. To insist that we have a purely "hands off" attitude is to admit a fundamental ethical defeat; it is to suppose that humans inevitably spoil and exploit all that we touch. If this is so, then it may well be that the long term goals of the animal rights movement are impossible to achieve. Rather, we need to learn from the details of our past mistakes and to build alternative models of ethical ecologically healthy co-existence.

The issues of peaceful co-existence and ethical exchange are broad and complex, and I do not intend to provide definitive answers in what follows but, rather, to explore some of these difficult issues in connection with the agricultural use of animals. The agricultural exploitation of animals is a particularly apt forum for exploring these issues, for several reasons. Both in terms of numbers of animals involved and extremity of suffering inflicted upon those animals, [1]

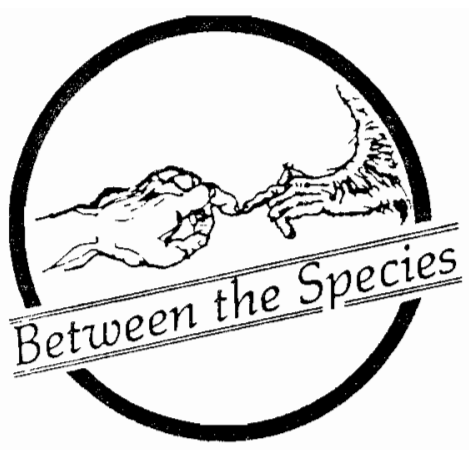

the agricultural use of aninals represents the most global violation of animal rights. Agricultural uses of animals are also among the most recalcitrant problems, since they are deeply entrenched culturally and economically. Agriculture is not an institution which can simply be eliminated, in the way that trapping, hunting, and whaling could be eliminated, while leaving the rest of our culture intact. We must gain sustenance, and however we do it, animals and the environment will be affected. Thus, we need alternative models, not simply abolition.

It might be argued, however, that agriculture is not a likely place to begin in exploring models for peaceful and ethical coexistence with animals, since agriculture is inherently destructive of the enviroment and exploitive of animals. Throughout history, agriculture has been damaging to the soil, ecosystems, and indigenous plant and animal species.[2] Marti Kheel has suggested that farming is a destructive patriarchal institution in which both animals and women are exploited for their reproductive ability. [3] And Paul Shepard sees in agriculture not only environmental destruction but the destruction of human character:

All agrarian societies share symptoms of homocentricity, illusions of omipotence, hatred of predatory wild animals, blunted body or blunted sensitivity, lack of interest in non-economic plants and animals, and the willingness to drudge, with its deep, latent re-

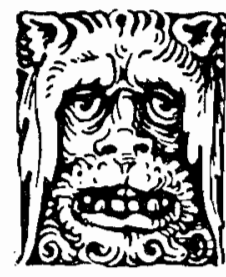

PHILOSOPHY 
sentments, crude mixtures of rectitude and heaviness, and absence of humor. [4]

If agxiculture is inherently damaging, then the best that we can do is to minimize it. Wenz has argued that the cultivation of land is almost universally detrimental to an ecosystem's health, and that cultivation should be minimized.[5] He sees this as providing an ecological argument for vegetarianism, since vegetarian diets require less cultivation of land. (All the land used to grow food for animals could be eliminated.)

But even if all that Shepard, Kheel, and Wenz say about agriculture as historically and currently practiced is granted, this does not show that non-destructive and non-exploitive forms of agriculture cannot be developed. Some institutions, such as slavery, are inherently exploitive and destructive.

But there is nothing inherently destructive about agriculture in the broad sense of "cultivation of land." It is only by having been practiced in particular ways, in conjunction with other human institutions, that agriculture has become exploitive.

Simply minimizing agriculture as Wenz suggests is not sufficient; a lesser evil is an evil nonetheless. And eliminating agriculture, besides being almost unthinkable, does not guarantee that the alternatives will be non-exploitive. Hunting and gathering have as much potential for exploitation as agriculture. Thus, alternative, non-destructive and non-exploitive forms of agriculture are not only theoretically possible, they are pragmatically necessary.

To begin to think about such alternatives, it may prove useful to consider what has gone wrong with contemporary agriculture, not merely from the perspective of the violations of animal rights but also from a broader ecological perspective. It is beyond the scope of this paper to document the suffering inflicted upon animals via intensive rearing practices, the health hazards visited upon humans by modern farming techniques and the environmental destruction and pollution produced by modern factory farms. These have been well documented by others.[6] Assuming a degree of familiarity with the deleterious effects of factory faming, I will direct my attention to underlying principles and causes. Similarly, space does not permit me to recapitulate the arguments, ably made by Tom Regan[7], among others, showing that the animals typically reared on factory farms have moral rights, including the right to life. While my analysis of the problem underlying modern agriculture does not directly involve this latter issue, my suggestions for alternatives will assume that other species do have fundamental moral rights, such as the right to life, and that to rear them for slaughter in any manner is, therefore, not a possible ethical option.

\section{Why Agriculture Cannot be Made Ecologically sound}

Increasingly, farms are large operations owned by businesspeople and corporations. It is well known that small, family farms are

being squeezed out of existence by big business. Approximately 650,000 farmers are forced out of farming each year. Currently, all the farming in the United States is done by less than $4 \%$ of the population. In contrast, in 1910, one third of the U.S. population lived and worked on farms.[9] Such large scale farming is ecologically damaging, and the notorious "factory farming" of animals is vastly less ethical and more environmentally damaging than diversified smallscale family farming.[9] Surveying this situation from the point of view of its effects, we might suppose that large scale agri-business could be made to be more ecologically sound--for example, through legislation mandating less use of harmulul pesticides, more setting aside of land for wilderness, more "organic" farming, and so on. It is one of Wendell Berry's important contributions to have shown why agri-business cannot be so reformed.[10] In much of my critique of contemporary agriculture, I will be drawing on his insights.

The owner of the large-scale, corporate farm is not a farmer but a businessperson. His/her main concern is profit. Since he/she does not live on the land, he/she is, at most, indirectly concerned with the harmful effects of the farming practices he/she dictates: if they do not cut into profits, he/she need not be concerned at all. $\mathrm{He} / \mathrm{she}$ need not be concerned with the healthfulness of the product he/she sells--as long as it sells. Nor need he/she be concerned with the long-term degradation of the land. If it is necessary to pour more chemicals into the land each year to make it produce as much as 
it did the last, then so be it. Indeed, the corporate farm fits into the broader corporate/capitalist picture very nicely, by consuming large quantities of non-renewable resources, such as petroleum and petroleum by-products. The corporations which manufacture petro-chemicals, antibiotics, and pesticides encourage the agri-businessperson to constantly increase consumption of energy sources in order to "boost yield."[11] Since agri-business is economically intertwined with these industries, there is a disincentive for energy conservation. Indeed, the self-sufficient farmer who produces his/her own food and has no need for the petrochenical industry is an anathema to the corporate establishment. As Berry has pointed out, it is typical of the agri-business approach to farming to take a solution, such as the use of animal wastes for fertilizer, and generate from it two problems: the pollution created by the dumping of animal wastes into streams and the "need" for chemical fertilizers. [12]

IThe agri-business establishment is not intentionally against healthy farming practices, of course. It is simply that health does not figure in any way in the businessperson's bottom line: profit. Servicing the agri-business community with dangerous chemicals, such as pesticides, chemical fertilizers, herbicides, and antibiotics, is highly profitable. since there is no internal pressure for ecologically sound farming within the agri-business establishment, the responsibility for protecting humans and the environment from the damaging effects of agribusiness farming is external; it rests in the hands of government agencies and independent organizations. But government agencies notoriously are staffed with former and future nembers of the agri-business and petro-chemical establishment. And the independent organizations are vastly out-lobbied and outfunded by special interests in the agriousiness and petro-chemical industries. [13]

But beyond these economic and political considerations, there lies another fundamental reason why agri-business cannot be reformed. The agri-businessperson, who neither lives on the land that he/she "farms" nor even knows much about farming, inevitably depends upon the agri-science specialist to tell him/her how to make the biggest profit. But the agri-scientist is not concerned with health and ecological balance. In part, this is because he/she is not paid to be concerned with such things. But beyond this economic allegiance, the agri-scientist cannot provide the type of knowledge needed for healthy farming. For, the agri-scientist is a specialist, and the specialist, by definition, has a narrow conception of problems and their solutions. As Berry points out, the specialist solves a problem without raising the question of the broad impact of the solution on the environment as a whole. For example, the specialist solves the problem of insect infestation by developing a pesticide, without raising the question of the long-term, cumulative effects of the pesticide on the environment and on animal species. The specialist sees his/her knowledge not only as specialized but also as ethically neutral. Within a system of specialists, it is no one's job to see that all the particular solutions work well for the whole.

But, as Berry's analysis shows, [15] agriculture is an important instance of a fundamental ecological fact: the complexity and interconnectedness of ecosystems. (An axion of ecology is that you can't do just one thing.) In the case of agriculture, there is a fundamental interconnectedness of the farmland, the surrounding wilderness, and the human communities. What is required, then, is an understanding of the whole system and these complex inter-relationships; something which the specialist cannot offer.

In the absence of a complex understanding of the environment within which farming takes place, the specialist imposes total control. The agri-scientist, like his sibling in biomedical research, views living organisms and land via a machine metaphor.[16] The idea of total control and the machine metaphor have a long history in science, [17] but for the specialist in agriculture, it can hardly be otherwise. For, as Berry argues, [18] the specialist puts himself in charge of just one possibility. All other factors, then, must be eliminated. This requires making chemical and physical boundaries, so that absolute control becomes at least a theoretical possibility. Weeds, insects, diseases, the weather, and people are unpredictable; leave them out. The natural mothering instincts of animals are unpredictable; leave them out and substitute automated farrowing pens and artificial insemination. What the agri-scientist fails to notice is that, aside from having left behind 
any semblance of an ethical regard for humans and other animals, he/she has also left behind health. For, as Berry points out, [19] in order to be healthy, crops and animals must have resistance; such resistance is a large part of what we mean by "health." By imposing boundaries and controls, the agriscientist eliminates this resistance. And we are increasingly forced to confront the calamitous results. [20]

Cannot the agri-scientist become cognizant of these factors, becoming more ecologically conscious and less specialized? We have seen a parallel development in modern medicine. Twenty years ago, the medical establishment's model for childbirth was also a model of total control. This model has been replaced by the model of natural childbirth, which does not allow total control but which eventuates in much healthier infants. It might be argued that the agri-scientist is already learning this lesson, as evidenced by the recent development of such programs as integrated pest management, $[21]$ which replaces harmful pesticides with natural insect controls, such as predatory insects, parasites, weather, crop rotation, and pest resistant crop varieties.

While agri-science might transcend the model of total control, there is a further factor which prevents the agri-scientist fron providing the knowledge for an ecologically healthy agriculture. The sort of training that the agri-scientist receives is not only specialized; in another sense, it is also generalized: it does not address itself to the particular properties of a field, of the surrounding environment or cormunity. But, as Berry argues, [22] the former must adapt crops to the particularities of the land. The good husbandperson is responsive to the health and needs of both land and community. Such particular knowledge cannot be put into an agricultural school curriculum. It is learned by living on the land. Lacking such knowledge, the agricultural scientist imposes a uniform and generalized model, removing trees and hedgerows, prescribing vast acres of mono-cultural crops, oversimplified and monotonous as tract homes.

No amount of technology can replace the particular knowledge which familiarity with the land provides. The agri-scientist could, however, combine his general knowledge with the particular knowledge of the small, family farmer. Agricultural schools could develop technologies, such as farm equipment, designed to the scale of the small farm. Such was the original purpose of the land grant colleges, [23] but they have been subverted by the agri-business establishment.

one clear consequence of the analysis so far is that a healthy agriculture must be labor intensive. We cannot entrust the health of the land to a few agri-business executives and agri-scientists and achieve a healthy outcome, just as we would not expect to achieve health by entrusting the care of. hundreas of people to one or two profitoriented doctors. While it may not be obvious, the current crisis is also a crisis for the environmentalist and even for the proponent of animal rights. For, with the passing of small farm cormunities will pass an important possibility: the possibility of an ecologically sound agriculture. When all farms are owned by a few corporate giants, there will be no turning back from the control of land and arimals (including humans) for sheer profit.

\section{A New Ethic for Agriculture}

Making farms smaller and more labor intensive is, of course, only a small part of what must be done in order to make farming ecologically healthy. Some of the further ingredients of healthy agriculture can be deduced from the negative critique of agribusiness. A healthy farm is part of the ecosystern surrounding it, and ecosystems, to be healthy, must be complex. A vast monoculture of grain robs the soil of essential nutrients, leads to loss of topsoil and erosion, and ultimately becomes "sick," requiring chenical fertilizers in order to produce. In contrast, a diversified farm in which fields are planted to a variety of species, including perennials and soilt-enriching grasses, is renewing to the soil. The principle of renewal and return, as Berry has pointed out, [24] is essential to healthy agriculture and is lacking in the agri-business approach.

But the ecological complexity of a healthy farm includes not only a diversity of plant life but a diversity of animal life. Healthy soil is full of micro-organisms and worms. An agriculture which does not rely upon pesticides requires the presence of many other species: of reptiles, birds, and amphibians to control insect population. And 
these latter creatures' members must be kept in balance by the presence of predators: raptors, weasels, mink, foxes, etc. These latter also control small, marmalian herbivores which can overrun crops. It is necessary to transcend the agri-scientist's vision of total control to see all these species as beneficial and, in fact, necessary to healthy agriculture, rather than as requiring removal.[25] A healthy agricultural landscape thus requires a mixing of the domestic and the wild, of fields, hedgerows, ponds, and trees, to provide habitat for the various species which are necessary to a healthy agriculture. It is these species, and not the traditional domestic farm animals, which I would argue are the most crucial animals in agriculture. It is hard to envision from our current practices such peaceful alliances, especially since farmers are responsible for so much "predator eradication." The felt need for predator control in agriculture arises from a number of sources, and the details of this controversy are beyond the scope of this discussion. Utilitarian arguments for and against the usefulness of hunting and trapping are beside the point, since hunting and trapping are in violation of the rights of the victims of these activities. However, one major source of the conflict between famers and wildlife revolves around the keeping of domestic animals, and this is a topic which must be considered. If farmers were to cease to keep domestic animals, such as sheep, cattle, and chickens, the need to control the foxes, wolves, and coyotes who occasionally prey upon them would vanish. What role can the traditional domestic farm animals play in an ecologically healthy, rights-respecting agriculture?

Domestic Farm Animals:

Out of the Frying Pan, into the Void?

The issue of our relations with domestic farm and companion animals is a vast, uncharted region, and our inability to cope with it is a measure of our inability to envision positive exchanges with other species. Critiques of our current relations with domestic animals show that these relations are exploitive and should be eliminated; they do not tell us what should replace our current institutions. Why do we have such difficulty envisioning positive relationships with animals? I believe that answering this latter question may help us clear away some of the barriers to working on this problem.

our current alienation may in part arise from our alienation from the land. Berry's analysis of this latter phenomenon may, therefore, be usefully extended to understand the inability to form positive exchanges with animals. Berry observes that both agriscientists and traditional conservationists (along with most of the rest of us) view the land as divided into two types: wilderness, which is to be left alone and unspoiled, and domesticated land, which is to be used and ultimately used up and defiled.[26] Neither conservationist nor agri-scientist has any well articulated idea where humans fit into the landscape. (In fact, both specifically exclude humans from agricultural and wilderness landscapes.) Needless to say, most of the rest of us do not feel a strong connection to the land. Many of us are "mobile," meaning that we do not identify with any place in particular. We feel unconnected and, therefore, not responsible to any particular place. our alienation has proceeded to the point that we are unaware of the ultimate sources of the food we consume. Farming is left to the specialists, and wilderness is a place to visit and observe, not a place to live and work.

In light of our separation from the land, it is not surprising that we find ourselves separated from animals. We extend the above-mentioned division of land to segregate animals into two types: those which are wild and can only be observed from a distance and those which are domesticated (i.e., exploited, treated like machines, and, like the farmland, ultimately used up). Just as "progress" has left us with no modern model which locates humans in an ecologically healthy landscape, we have no idea how to engage in non-exploitive exchanges with animals. We must think of those two problems simultaneously, if we seek an ecologically healthy agriculture, since, as we have seen, an ecologically healthy agriculture requires the presence of many animal species. Ecological health must necessarily be the framework within which ethical and non-exploitive interaction with animals is defined.

In light of these considerations, we must examine carefully the notion of "domes" tic animal." Under one construction, a domestic animal is simply one which has been genetically altered in such a way that its 
behavior and appearance is quite different from its wild relatives. To this fairly neutral, biological definition, we can add the undeniable fact that the modifications have all been wrought with the goal of exploiting the animals for various purposes. In genetically altering other species, we have not had in mind the purpose of improving their overall well-being. We could not, of course, accomplish this as well as natural selection does, anyway. Rather, our purpose has been to further our own ends in extracting eggs, meat, milk, and garnent materials. The very concept of "domestic animal" is thus laden with connotations of degradation and exploitation. One might ask whether it is not too severe to view them as fundarnentally degraded, as "genetic goofies," as shepard puts it. [27]

Let us recall, though, that the same sorts of things can be said about domestic land. It is the land which is altered to our purposes, which is generally degraded and exploited. It need not be. The alteriative involves a softening of the distinction between domestic and wild--an accomodation to the wild and uncontrolled in the domestic landscape. Similarly, we reed to develop a recognition of relationships with animals that are neither entirely wild (outside the boundaries of our landscape) nor entirely domesticated. There is another sense of "domesticated" which might be invoked here: the sense of causing to feel at home, or naturalization. Among domestic animals, there may be species which can be accommodated by us in non-exploitive ways. It is necessary to examine each case individually, taking into account the effects of including domestic animals on the ecosystem (since domestic animals can upset the balance and displace local wild populations). Obviously, a number of other factors must be considered, as well.

First, we might raise the question of the point of perpetuating domestic species. I have nothing definitive to say on this point, other than that if they can be maintained non-exploitively, then the companionship they offer may be a valuable force in furthering and maintaining the goals of anithal rights. While philosophical arguments and respect for wildlife are valuable tools in furthering animal rights, many people are moved to action because they have known and cared about particular animals. Without such close contacts, animal rights issues may become abstract and distant.

Second, we must address the issue of a "fair exchange" with domestic animals. This is especially important in the case of "farm" animals. For, if they are to be a part of farms, they should contribute materially and not simply become companion animals, for two reasons. Farms are, among other things, economic institutions, and they must be economically viable. Those who live on the farms must contribute. Further, even if it were economically viable, keeping farm animals as companions, or "out of the goodness of our hearts," inay well lead to exploitation. The fair exchange problein is exceedingly difficult, and any solutions offered will be suspect as long as humans own domestic animals. Ownership implies a kind of power incompatible with a domestic animal's lobbying an effective complaint regarding an unfair exchange. Thus, a necessary antecedent condition to effectively working out the fair exchange problem may be the abolition of ownership of domestic animals and its replacement with some other model, such as that of stewardship or adoption.

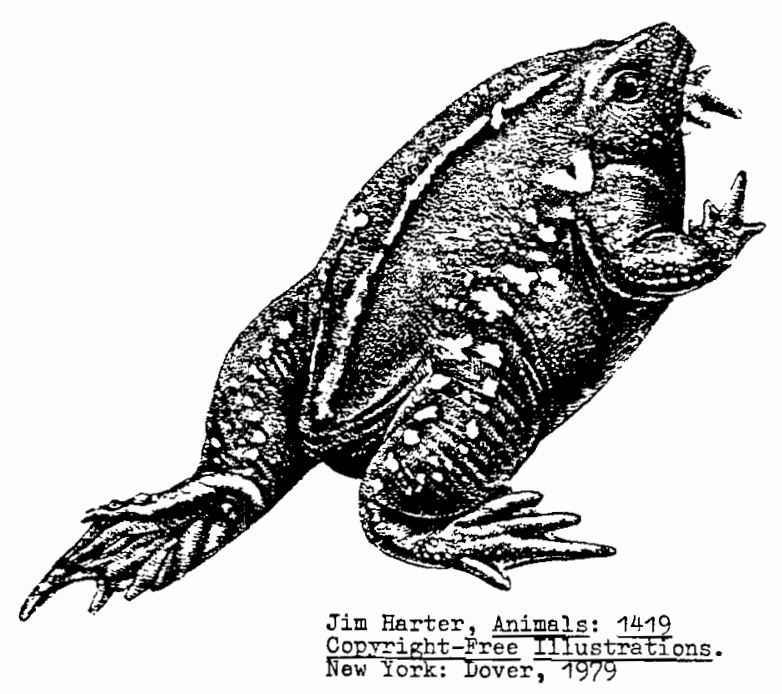

Even assuming that we could develop a legal model allowing advocacy of the interests of domestic animals, the issue of their genuine interests will be complicated by their very domesticity. Their interests have so long been warped to serve ours; how can we determine whether it is fair to take the eggs from donestic chickens or the wool from domestic sheep? It is part of their "warped" telos to accept us as their protectors. 
Should we respect this interest or attempt to eliminate it?

In addition to all the difficulties in determining the interests and rights of domestic animals, there is the further issue of ecological health to consider. Those arguing for the rights of animals should not ignore environmental issues, nor should environmentalists ignore issues of rights. It is beyond the scope of this essay to show that these two perspectives can be reconciled, but it is one of the lessons of Berry's analysis regarding specialization that we must not impose specialized solutions where ecological complexity is involved. Thus, we must inquire whether keeping domestic animals can be ecologically enriching.

Berry points out that the examples that we have seen to date of ecologically sound and energy independent agriculture use plants and domestic animals together.[28] Animals' waste provides a natural fertilizer for land under cultivation, and work animals provide energy independence. (Amish farmers who plow using horses do not have to worry about the price of OPEC oil.) It is likely that the functions that these animals serve in producing an ecologically sound agriculture can be achieved in other ways. The development of farming techniques which require much less cultivation and fertilizer, through the use of perennial poly-cultures, [29] may obviate the need for animal wastes. Alternatively, techniques may be developed for the safe use of human wastes. Work animals can certainly be replaced in energy efficient ways, e.g., by human laborers using small, energy efficient vehicles.

In other words, it is likely that there are a number of ecologically sound agricultural models, some of which incorporate domestic farm animals and some of which do not. Our choices among these models must be constrained not only by ecological considerations but also by considerations of the rights of both the domestic and wild animals involved. Given the complexity of the issues involved, such models cannot yet be worked out in detail--especially not by philosophers working in isolation. But, as Berry has shown, they cannot be worked out by teams of agricultural specialists, either. In order to develop these models, we must cross the lines of specialization which have prevented ecologically sound solutions to environmental problems in agriculture and begin to talk and work with both farmers and ecologists.

While the task of developing non-exploitive exchanges with animals is fornidable, I hope that I have succeeded in arguing for the importance of doing so. The development of such models may appear utopian, but I think that it is no more utopian than the model of abolition which it attempts to transcend. Until such positive models are developed, the goals of abolition may thenselves appear impossible, in that they create a void without telling us how it will be filled.

Notes

1. Jim Mason and Peter Singer, Animal Factories (New York: Crown Publishers, 1980).

2. Paul Shepard, The Tender Carnivore and the Sacred Garne (New York: Charles Scribner's Sons, 1973).

3. Marti Kheel, "An/Aesthetics: The Representation of Women and Animals, "Between the Species I/2 (1985), p. 41.

4. Shepard, op. cit., pp. 19-20.

5. Peter Wenz, "An Ecological Argument

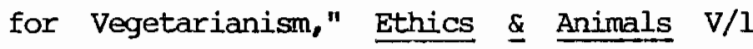
(1984), p. 2 .

6. Mason and Singer, op. cit.; also see Orville Schell, Modern Meat (New York: Random House, 1984).

7. Tom Regan, The Case for Animal Rights (Berkeley: University of California Press, 1983).

8. Wende1l Berry, The Unsettling of America (New York: Avon Books, 1978), p. 63.

9. Ibid. (Of course, this is a matter of degree. Family farming also gave us the dust bowl.)

\section{Ibid., Chapter 5.}

11. Lewis Regenstein, America the Poisoned (Washington, D.C.: Acropolis Books, 1982).

12. Berry, op. cit., p. 62 . 
13. Regenstein, op. cit., p. 124.

14. Berxy, op. cit.. pp. 19-21.

15. Ibid.. p. 46.

16. In the March, 1978, issue of the National Hog Famer, I. J. Taylor, export development manager for wall's Meat Co., advises that

the breeding sow should be thought of, and treated as, a valuable piece of machinery whose function is to purnp out baby pigs like a sausage machine (p. 46).

17. Brian Klug, "Iab Animals, Francis Bacon and the Culture of Science," Listening 18/1 (1983).

18. Berry, op. cit., p. 70.

19. Ibid., p. 72 .

20. See Schell, op. cit.., Chapter 1, for a discussion of the production of antibioticresistant strains of bacteria via the routine feeding of low-dose antibiotics to intensively reared farm animals.

21. Regenstein, op. cit.., p. 125.

22. Berry, op. cit., p. 43.

23. Ibid., Chapter 8.

24. Ibid.. p. 89 .

25. The ideal of total control is an illusion, in any case. Predator eradication usually results in invasion by heartier predators. Insects become resistant to pesticides, while the wildlife that would have helped to control thern are killed. The red wolf was "eradicated" from North America; the more adapted, harder to eradicate coyote is now replacing the red wolf in parts of the continent formerly devoid of coyotes.

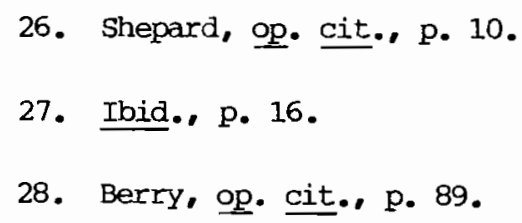

29. Wendell Berry, The Gift of Good Land (San Francisco: North Point Press, 1981), pp. 228-48.

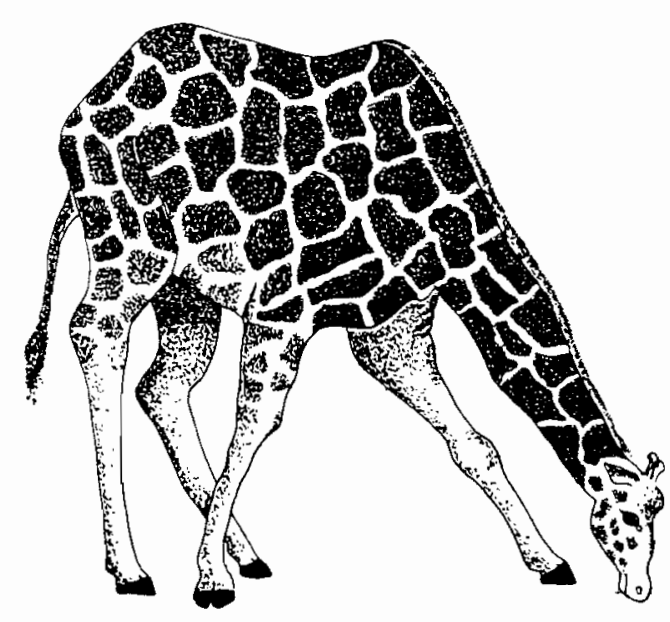

BLATZ continued from page 16

14. Just who is open to such influence and when? As others have suggested, we get some idea of the answer to this question by a study of moral and legal defenses. This source has the danger of leading us in a circle, however. Therefore, we would do best to look more carefully at the use and potential of ethics to facilitate aims and pursuits in social arrangements, including practices of holding people to account. Where there is such potential, we have people open to the influence in question. Unclear or borderline cases will call, as usual, for decisions within the spirit of the project at hand, of maximally facilitating aims and pursuits by the guidance of reasons.

15. What aims and pursuits? Please see the next section and the work referred to in note. 16 .

16. A more detailed account of the basic issues here has been given in a number of my recent papers. The most thorough version is in a paper entitled "Conflict Resolution and Agriculture," presented at the nost recent Northwest Conference on Philosophy.

17. Francis Moore Lappe, Diet for a Small Planet (New York: Ballantine Books, 1982).

18. I would like to thank Steve Sapontzis and Stan Dundon for their comments on an earlier version of this paper. 